\title{
Jean-Claude Montanier, Geoffrey Samuel, Le contrat en droit anglais
}

Grenoble : Presses Universitaires de Grenoble, 1999

\section{Rosalind Greenstein}

\section{CpenEdition}

\section{Journals}

Édition électronique

URL : http://journals.openedition.org/asp/3602

DOI : $10.4000 /$ asp.3602

ISBN : 978-2-8218-0410-4

ISSN : 2108-6354

\section{Éditeur}

Groupe d'étude et de recherche en anglais de spécialité

\section{Édition imprimée}

Date de publication : 1 novembre 2009

Pagination : 135-136

ISSN : 1246-8185

\section{Référence électronique}

Rosalind Greenstein, « Jean-Claude Montanier, Geoffrey Samuel, Le contrat en droit anglais », ASp [En ligne], 56 | 2009, mis en ligne le 06 décembre 2009, consulté le 02 novembre 2020. URL : http:// journals.openedition.org/asp/3602 ; DOI : https://doi.org/10.4000/asp.3602

Ce document a été généré automatiquement le 2 novembre 2020.

Tous droits réservés 


\section{Jean-Claude Montanier, Geoffrey Samuel, Le contrat en droit anglais}

Grenoble : Presses Universitaires de Grenoble, 1999

Rosalind Greenstein

\section{RÉFÉRENCE}

Montanier, Jean-Claude et Geoffrey Samuel. 1999. Le contrat en droit anglais. Grenoble :

Presses Universitaires de Grenoble. ISBN 2-7061-0832-1. 143 p. 
1 Les quatre ouvrages présentés ici ont en commun le fait de traiter de la langue du droit, de manière différente et complémentaire et en visant des publics hétérogènes. Bien sûr, le contenu des livres ainsi que leur lectorat peuvent se recouper, d'où la question suivante: comment un lecteur potentiel va-t-il faire son choix? Tout d'abord, en regardant le titre; ensuite, en lisant la quatrième de couverture. Et c'est là que le bât blesse. Car soit par ignorance, soit parce que confrontés à des impératifs commerciaux mal maîtrisés, les éditeurs (à moins que ce ne soit les auteurs) donnent souvent l'impression que le livre s'adresse à plusieurs publics à la fois, au risque de décevoir les lecteurs qui, par conséquent, hésiteront à acheter d'autres livres à l'avenir. Quels sont, donc, les quatre ouvrages et comment peuvent-ils

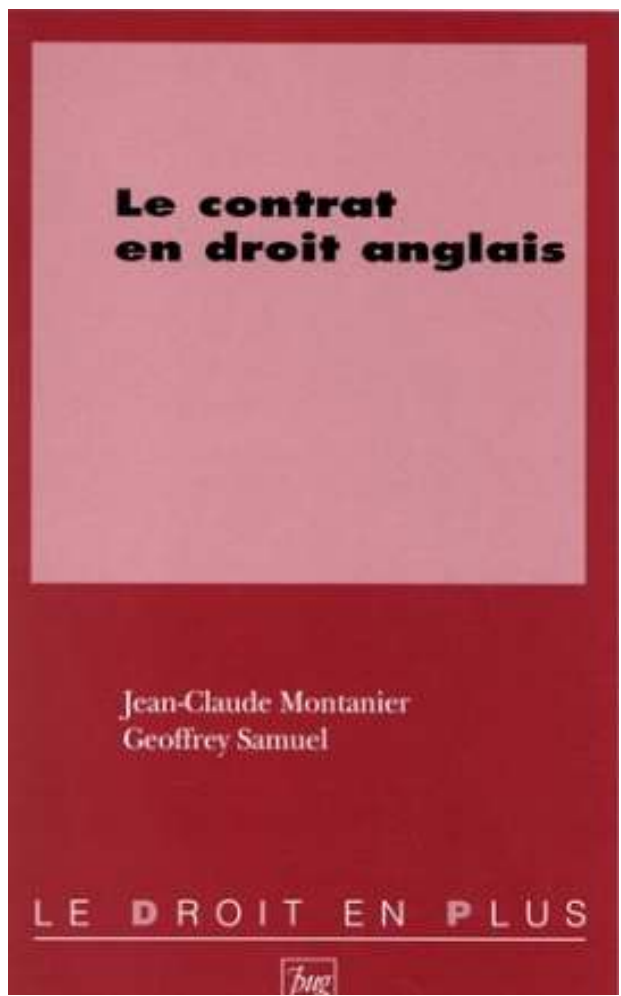
répondre aux besoins et aux attentes de la communauté des anglicistes de spécialité?

2 L'originalité du troisième ouvrage, Le contrat en droit anglais, réside dans le fait qu'il a été rédigé, en français, par deux professeurs de droit, l'un anglais, l'autre français, chacun connaissant le système juridique de l'autre. Le but du livre, énoncé clairement sur la couverture, est de présenter le contrat anglais à un lectorat francophone, tâche redoutable d'ailleurs, tant les institutions, les mentalités, l'histoire et la méthode sont différentes entre un système de tradition romano-germanique et un système de common law. Pour ce faire, les auteurs ont décidé d'emblée que certains termes ne se traduisent pas et ils partent du principe que le lecteur a déjà quelques connaissances en anglais.

3 Après une courte introduction qui passe rapidement en revue la notion de "contrat » dans les deux systèmes - définition, classification, les actions en common law et les equitable remedies - le livre se décline en deux grandes parties : la première présente la formation d'un contrat simple, de manière à dégager des principes permettant la comparaison avec ceux du droit français ; la seconde est consacrée aux effets du contrat et donne l'occasion de noter des divergences sensibles entre les deux systèmes.

La première partie - La formation du contrat - est divisée en trois chapitres. Dans le premier, «Les élément essentiels du contrat », nous y trouvons notamment la capacité, l'offre, l'acceptation, la promesse vague, la consideration, estoppel in equity et l'intention de contracter. Le deuxième, "Les vices du contrat ", examine, entre autres, les void et voidable contracts, unenforceable contracts, misrepresentation, l'erreur, le dol et la violence. Le troisième, «La responsabilité contractuelle», traite de la responsabilité contractuelle, la responsabilité délictuelle et la responsabilité quasi contractuelle, sans oublier la responsabilité en equity. 
La seconde partie - Les effets du contrat - est également divisée en trois chapitres, dont le premier, «La structure et l'interprétation », concerne les règles d'interprétation, les conditions et warranties, les clauses d'exonération, la protection des consommateurs, les penalty clauses et les implied terms. Le deuxième, "L'effet relatif du contrat » étudie la notion de privity of contract, le droit des biens, le droit commercial, les groupes de contrats... tandis que le troisième et dernier chapitre, "L'inexécution », est consacré à la rupture, la dissolution par consentement mutuel, l'impossibilité d'exécution (frustration), le dommage et l'enrichissement sans cause, pour en citer quelques exemples.

6 Une conclusion sommaire rappelle au lecteur qu'un ouvrage aussi court (132 pages de texte) ne peut qu'effleurer le sujet et ne peut pas répondre à toutes les questions qui se posent, dont celle de savoir si les deux notions sont, ou non, trop loin l'une de l'autre pour envisager, un jour, une harmonisation du droit privé en Europe. Bien que publié il y a une dizaine d'années, le livre reste d'actualité, comme on peut le voir en lisant la citation, à la dernière page, de Paul-André Crépeau, juriste canadien, qui s'interroge sur « une renaissance de la moralité contractuelle, la recherche d'un équilibre, le refus de l'exploitation de l'homme par l'homme, la conscience accrue de situations inéquitables, la prévention de l'abus ou la promotion du raisonnable » (p. 38) ${ }^{1}$.

\section{NOTES}

1. Crépeau, Paul-André. 1998. Les Principes d'unidroit et le code civil du Québec: valeurs partagées? Scarborough, ON, Canada : Carswell.

\section{AUTEURS}

\section{ROSALIND GREENSTEIN}

Université Paris 1 Panthéon-Sorbonne 